\title{
Supplemental table 1:
}

\begin{tabular}{|l|c|c|c|c|c|}
\hline Vector Name & $\begin{array}{c}\text { Lot } \\
\text { number }\end{array}$ & $\begin{array}{c}\text { VP/IU } \\
\text { ratio }\end{array}$ & $\begin{array}{c}\text { Transgene } \\
\text { sequence }^{*}\end{array}$ & $\begin{array}{c}\text { Purification } \\
\text { method }\end{array}$ & $\begin{array}{c}\text { Transgene } \\
\text { expression }\end{array}$ \\
\hline Ad35.Ebo(Z) & G430-016 & 10 & confirmed $^{\text {CsCl purified }}$ & verified \\
\hline Ad35.Mar(A) & G748-037 & 7 & confirmed & $\mathrm{CsCl} \mathrm{purified}$ & verified \\
\hline Ad35.Ebo(SG) & G619-019A & 9 & confirmed & CsCl purified & verified \\
\hline Ad35.Ebo(IC) & H539-037A & 3 & confirmed & CsCl purified & verified \\
\hline Ad35.Mar(R) & H700-003A & 6 & confirmed & CsCl purified & verified \\
\hline Ad26.Ebo(SG) & H539-074A & 18 & confirmed & CsCl purified & verified \\
\hline Ad26.Ebo(Z) & H001-060A & 11 & confirmed & CsCl purified & verified \\
\hline Ad26.Ebo(IC) & H539-085A & 24 & confirmed & CsCl purified & Verified \\
\hline Ad26.Mar(A) & H129-067A & 10 & confirmed & CsCl purified & verified \\
\hline Ad26.Mar(R) & H539-092A & 12 & confirmed & $\mathrm{CsCl} \mathrm{purified}$ & verified \\
\hline Ad35.empty & G849-053A & 3 & confirmed & $\mathrm{CsCl} \mathrm{purified}$ & NA \\
\hline Ad26.empty & G737-070A & 26 & confirmed & CsCl purified & NA \\
\hline
\end{tabular}

Transgene integrity was verified by sequence analysis.

NA: Not applicable 